\title{
Second International Symposium on Quantitative Biology of Metabolism (Helgoland, 1965): opening address
}

\author{
OTto KinNe
}

Biologiscbe Anstalt Helgoland, Zentrale, Hamburg-Altona

Ladies and Gentlemen

Welcome! Welcome to the island Helgoland; welcome to the Marine Station of the Biologische Anstalt Helgoland!

On behalf of the organizing committee - consisting of Dr. LOCKER, Professor KRÜGER and myself - I would like to thank you for accepting our invitation to participate in the Second International Symposium on Quantitative Biology of Metabolism. It is a great pleasure and honor for us to see such an impressive diversity of biological and medical disciplines represented here - represented in fact by very able and distinguished scholars from 16 different nations.

The idea of initiating a bi-annual series of international symposia concerned with a wide scope of quantitative aspects of metabolism was conceived only a few years ago. It was stimulated by the apparent need for a permanent interdisciplinary platform providing an opportunity for a small group of active investigators to report, discuss and evaluate new pertinent information; it was also stimulated by the success of a comparable series of symposia initiated previously in the United States.

In the last few decades the developments of our scientific disciplines have been characterized by a spectacular exponential growth phase. The tremendous increase in scientific activities has led to an ever-increasing amount of new information becoming available each year. The compelling need to relate, evaluate and "computorize" this multiplicity of new information forces us to look for appropriate techniques which allow the application of useful concepts of generalization, formalization and abstraction. In essence, such techniques must be quantitative, that is, mathematical in nature; the language of formalization and abstraction is mathematics.

Mathematical formulations, concepts and models have become more and more important as scientific tools and have already proved their indispensability in modern fields of research such as cybernetics and information theory. In recent years they have also been employed successfully in regard to the study of metabolic processes and 
ecological phenomena. We are convinced that our emphasis on quantitative aspects of metabolism will result in new insights into the principles governing complex biological systems and open up additional avenues and vistas beyond our present horizon.

Various fields of biology and medicine - at least up to this date - resist a quantitative treatment, however, because they are primarily based on "qualitative" aspects. This is particularly true for such important areas as taxonomy, morphology, phylogeny and behavior. Certainly we should not make the mistake of considering and discussing biological and medical problems here without any reference to such fields or the "qualitative" properties of the living systems under consideration.

The "International Helgoland Symposium 1965" was made possible through financial support from the Bundesernährungsministerium in Bonn, the O'sterreichische Gesellschaft für Reine und Angewandte Biophysik and the Osterreichische Studiengesellschaft für Atomenergie $\mathrm{GmbH}$, both in Vienna. The community Helgoland, its mayor, Herr RrCKMERs, and its town-councillor, Herr BoTTER, have again supported us wholeheartedly. As a gesture of welcome to the participants of this symposium, the Helgolanders have raised the flags of all nations represented here on the main island pier; they have invited us to a reception and to attend the Helgoland exhibition; in addition, they have organized an island round trip for all participants in their lamplighted fishing boats and put their large heated sea water swimming pool at our disposal. All this support is gratefully acknowledged. Please let me add a word of special thanks to Dr. A. Locker, who has carried the major load with respect to the issuing of invitations and the working out of the detailed program, and to Professor F. KR ÜGER and his wife, who have done their utmost to help with the local organization.

As I have pointed out on previous occasions, it is not by mere chance that this international symposium is being held on Helgoland. The research activities of the Biologische Anstalt Helgoland are to a significant extent concerned with quantitative aspects of biological systems in the sea and the extent to which their functions and structures may be modified by environmental factors. Several of our scientists have just started an extensive, long-term study of the processes of production, transformation and decomposition of organic matter in oceans and coastal waters; another group is working on detailed analyses of physiological and ecological performances of key-organisms under controlled conditions in the laboratory. Future plans call for even more extensive work in the rather young and promising field of experimental ecology.

In addition, the island Helgoland is an ideal meeting place. There are no trains, street cars, buses or automobiles; there are practically none of the distractions typical of big cities; the air is refreshingly clean and stimulating to intellectual activities; and finally, it is quite difficult for any symposium participant to evade our sessions and discussions - to escape from Helgoland, he would have to use a ship or swim all the way back to the mainland!

Please let me add a few words about our institution. The Biologische Anstalt Helgoland was founded in 1892. Its present activities are devoted to (1) basic research in all fields of Marine Biology; (2) advancement of knowledge on the life in the sea by offering (a) research space to visiting scientists, (b) course rooms, material and advice to courses organized by universities, (c) conducting own courses on marine biological 
subjects, (d) supplying scientific institutions with living or fixed marine material, (e) maintaining a public aquarium also used for teaching and research. The Biologische Anstalt Helgoland consists of three groups of facilities: He a dquarters (Zentrale), Marine Station (Meeresstation) and Litoral Station (Litoralstation), all located in strategically well-chosen localities.

$\mathrm{Headquarters}$ is located in Hamburg, one of the largest cities in Europe, having a modern airport, a big university and a multitude of other scientific and cultural institutions. The main building houses a number of laboratories and staff offices, a circulating sea water system, special experimental rooms and a small library as well as the Director's permanent quarters and the administration.

The Marine Station on Helgoland has some 24 laboratories, 15 of which are available for visiting scientists, a large running sea water system, a public aquarium and a moderate library (which is presently being enlarged); among the various special rooms are 7 temperature-controlled rooms, 2 course rooms and several sorting and maintenance rooms for animals and plants. The laboratories for visiting scientists are equipped especially for ecological, physiological and biochemical work. We shall be showing you around in just a few moments. In addition to the main building, there are a harbor laboratory, a guest house with 25 rooms and 9 houses for permanent staff members on Helgoland. Construction of a student dormitory will start in the next few months, and a new building for experimental ecology is being planned. Around the island we can find the richest marine fauna and flora within the boundaries of Germany; the primary substrates are rock (red sandstone), gravel and sand.

The Litoral Station in List on the island Sylt is housed in an old harbor building. It comprises facilities for three scientists, 2 course rooms and a small circulating sea water system. In the near future, its present building will be modernized and enlarged, and more facilities will be made available for visiting scientists. The area around List is characterized by dunes, sandy beaches and extensive mud flat areas. Thus the Litoral Station offers access to quite different habitats and working conditions than does the Marine Station on Helgoland.

The staff of the Biologische Anstalt Helgoland consists of some 100 persons, 23 of whom are scientists. The scientific staff is subdivided into 7 different divisions: Zoology, Physiology, Botany, Microbiology, Planktology, Ichthyology and Radiation Biology. Our institution maintains a $24 \mathrm{~m}$ long research vessel and several smaller motor boats; a new some $37 \mathrm{~m}$ long research vessel will soon be under construction.

Should any of you be interested in working on Helgoland or on Sylt, you will be most welcome to do so. Our facilities are available for colleagues from Germany as well as from any other country.

Ladies and Gentlemen! I do not want to take up more of our precious time. The many interesting papers announced in our program promise stimulating discussions and warrant the hope that this international meeting will significantly advance and enrich our knowledge in the field of quantitative biology. May each participant enjoy giving and receiving and may this symposium be shone upon by a similarly good and lucky star as was the first one. It is with these wishes that I open the Second International Symposium on Quantitative Biology of Metabolism. 